\title{
The structure of qualitative studies: a bibliometric pattern of biomedical literature
}

\author{
A estrutura de estudos qualitativos: \\ um padrão bibliométrico da literatura biomédica
}

Rodrigo Almeida Bastos (http://orcid.org/0000-0002-6159-8048) ${ }^{1}$

Vera Lucia Pereira Alves (http://orcid.org/0000-0003-4293-1439) ${ }^{2}$

Rômulo Magnus de Castro Sena (https://orcid.org/0000-0001-6802-0786) ${ }^{2}$

Juliana Vasconcellos Freitas de Jesus (https://orcid.org/0000-0001-9136-478X) ${ }^{1}$

Larissa Rodrigues (https://orcid.org/0000-0001-8714-7010) ${ }^{1}$

Fernanda Garanhani de Castro Surita (https://orcid.org/0000-0003-4335-0337) ${ }^{1}$

Egberto Ribeiro Turato (http://orcid.org/0000-0002-7857-1482) ${ }^{2}$

\footnotetext{
${ }^{1}$ Departamento de Ginecologia e Obstetrícia, Faculdade de Ciências Médicas, Universidade de Campinas (UNICAMP). R. Tessália Vieira de Camargo 126, Cidade Universitária. 13083-887

Campinas SP Brasil. almeidabastos.rodrigo@ gmail.com

${ }^{2}$ Departamento de Psicologia Médica e Psiquiatria, Faculdade de Ciências Médicas, UNICAMP. Campinas SP Brasil.
}

\begin{abstract}
The lack of knowledge in the biomedical literature regarding the validity of qualitative studies might be related to the lower number of qualitative studies that have been published. The criticisms range from a lack of theoretical depth to the superficial discussions of empirical findings. The aim of this study was to explore the bibliometric entities and the trends in the structure of qualitative research in the biomedical literature. A bibliometric analysis and mapping of the biomedical literature were used. The number of studies selected was 1,725. The heath themes with the most publications included Health Management (12\%) and Women's Health (9.8\%), while the authors of the studies had academic affiliation in 76 different countries. The sample sizes were between 11 and 20 participants (27.13\%) and the Grounded Theory framework (9.04\%) stood out. The improved structuring of a qualitative research extends the effective communication between health providers and researchers, and support in the management of clinical situations. Key words Evaluation Studies as Topic, Qualitative Research, Research Design, Medical Libraries, Health Sciences
\end{abstract}

Resumo A dificuldade de entendimento na literatura biomédica sobre a validade dos estudos qualitativos pode estar relacionada ao menor número de estudos qualitativos publicados. As críticas também vão desde a falta de profundidade teórica até discussões pouco objetivas de descobertas empíricas. O objetivo deste estudo foi explorar padrões bibliométricos e as tendências na estrutura das pesquisas qualitativas na literatura biomédica. Utilizou-se análise bibliométrica $e$ mapeamento da literatura biomédica. O número de estudos selecionados foi 1.725. Os temas de saúde com mais publicações incluíram Gestão em Saúde (12\%) e Saúde da Mulher (9,8\%), enquanto os autores dos estudos tiveram afiliação acadêmica em 76 países diferentes. O tamanho da amostra mais observado foi de 11 a 20 participantes $(27,13 \%)$ e o referencial da Grounded Theory (9,04\%) o mais utilizado. A estruturação aprimorada de uma pesquisa qualitativa amplia a comunicação eficaz entre profissionais de saúde e pesquisadores, além de apoiar o gerenciamento de situações clínicas.

Palavras-chave Estudos de Avaliação como Tópico, Pesquisa Qualitativa, Desenho de Pesquisa, Bibliotecas Médicas, Ciências da Saúde 


\section{Introduction}

Over the past 40 years, there has been an interesting academic dynamic shift in the biomedical literature. Since 1975, according to search results in the PubMed database, and using the descriptor "qualitative study", there has been an increase in the number of studies using qualitative methods. This shift might indicate that clinical researchers are gradually realizing the importance of in-depth knowledge of some social phenomena. These phenomena may include social or individual experiences, thoughts, meanings and the attitudes of individuals or groups that do not fit into the formal quantitative evaluation ${ }^{1}$.

The practice in public health also realizes the importance of observing subjective situations in the care process. This observation includes the need to investigate subjective strategy for action. This context is another factor that gives importance to the knowledge of the characteristics and the process of qualitative research in health ${ }^{1,2}$.

Perhaps because of paradigmatic issues, the emphasis of health research is on numerical data. However, professional practice has increasingly needed contributions from qualitative research ${ }^{3}$. Engagement of qualitative research in health care supports evidence-based practices ${ }^{4,5}$, optimizes patient management ${ }^{6}$, increases patient safety ${ }^{7}$, optimizes health promotion, and improves communication as well as decision-makings ${ }^{8}$.

In fact, qualitative studies might allow researchers to understand the meaningsattributed by the subjects to their actions ${ }^{1,9}$. However, the lack of knowledge among health science researchers with regard to the qualitative approach generates a reductionist view of this type of research. Thus, the validity of qualitative research is sometimes questioned using the erroneous assumption of its non-reproducibility and the impossibility of generalizing its findings ${ }^{9}$. Characterizing the studies with a qualitative approach that focus on exploring the subjectivity of an experience in a health settinghelps the reader to understand thevalidity of this approach as a scientific method.

There is a rationale for the reason why a lower number of qualitative studies have been published. A possible causal factor is the lack of knowledge in the biomedical literature in relation to the validity of these studies. The criticisms range from a lack of theoretical depth to the superficial discussions of empirical findings ${ }^{9}$. In this sense, the aim of this study was to explore the bibliometric entities and the trends in the structure of qualitative research in the biomedical literature.

\section{Methods}

This is a bibliometric study which maps the production of scientific literature into patterns. Bibliometric analysis does not produce original evidence but produces other complementary outcomes, such as the most productive topics, authors, countries, production maps, and science landscapes ${ }^{10,11}$.

\section{Eligibility criteria}

Studies which referred to the "qualitative study" in their content, whether primary articles, theoretical or revision, over a six-month period, were included. Quantitative or mixed articleswere excluded, including those that referred to qualitative steps. These studies had no relationship with the qualitative methods that were the focus of the present study.

\section{Information sources}

A search for articles published in journals indexed to PubMed was performed. This database is the broadest international database of biomedical literature. The search included the period from January to June 2016, no contacts were made with the authors of the studies and the grey literature was not used.

\section{Search strategy}

The descriptor used was "Qualitative Study". The findings were filtered for Text availability (Abstract) and Publication dates (From $01 / 01 / 2016$ to $06 / 30 / 2016$ ). The researchers of the data collection team (05 people) received appropriate training. The articles were distributed among the researchers and the search strategy was standardized considering the characteristics studied, based on the abstracts of the studies. If there were any divergences regarding the information, the main author analysedthe study and made the final decision.

\section{Study records}

Data management: The data collection management was performed using EndNote. The data collection team was trained by the main author, who controlled the entire process.

Selection process: There was no screening process for the findings. All studies were included for the data collection process, with the methodological specificities constituting the variables. 
Data collection process: A pilot study was performed in order to improve the data collection strategy. A total of 20 articles were randomly selected from the filters. The 20 abstracts were individually considered by two of the authors of this study, who defined the variables. After the pilot study, the data collection was systematized and the work was distributed among the team.

\section{Data Items}

Ten variables were evaluated and related to two axes: 1) Characteristics of the journals and authors; and 2) Characteristics of the qualitative studies. The variables of the $1^{\text {st }}$ axis were: Journals, health themes, knowledge areas, authors' academic affiliation and the verb used in the general objective. The variables of the $2^{\text {nd }}$ axis were: sample size, software use, framework, participants and data collection strategy. All data were stored in the Statistical Package for the Social Sciences (SPSS), version 13.0 for Windows. Frequency and bivariate analyses were performed with the support of a statistician. The test for significance was two-tailed and $\mathrm{p}<0.05$ was considered significant.

\section{Outcomes and prioritization}

Frequency and comparative analyses were performed to describe the structure of the articles and the characteristics of the journals and authors of the qualitative studies in the biomedical literature.

\section{Results}

A total of 1,870 articles were screened, with 1,725 selected for the study. The articles were stored using the EndNote platform for the management of the data collection process and for the organization of the final individual review. Figure $1 \mathrm{de}-$ scribes the steps followed until the final selection of the study articles.

\section{Characteristics of the journals and authors}

A total of 620 biomedical journals published qualitative studies between January 2016 and June 2016. Five journals were responsible for $12.1 \%(n=207)$ of all the publications (Table 1$)$. The diversity of characteristics highlights the interest in analysing the verb used in the general objectives of each study. Technical and structural discussions as well as epistemological reflections can be developed from the analysis of the verbs. The verb "To Explore" (37.7\%) headed the list of 131 different verbs used in the qualitative studies analysed. The five main verbs appear in $70 \%$ of the analysed publications.

The heath themes most published were related to health management $(12 \%)$, women's health $(10 \%)$, mental health $(10 \%)$, health education $(7 \%)$ and infectiology $(6 \%)$. Table 2 shows the health knowledge areas that published each theme $(\mathrm{p}<0.001)$.

There were many multi-centre studies which involved authors of different nationalities. The authors had academic affiliation in 76 different countries. Figure 2 describes the most frequent among the evaluated articles. The five main countries represented $62 \%$ of the qualitative studies evaluated. The list was headed by the United States (22\%) and has the representation of the 5 continents. Iran (5\%) showed its growth in scientific production as the first Asian representative among the five main publishing countries. It was the most representative among the emerging countries and was followed by Brazil $(1.5 \%)$, which appeared in the $12^{\text {th }}$ place according to representativeness.

\section{Characteristics of the qualitative studies}

The structural characteristics of the qualitative studies, sample size, software use and the framework used are often divergent themes among qualitative researchers, highlighting their importance. The sample sizes were between 11 and 20 participants $(27.13 \%)$, with the Grounded Theory framework (9.04\%) and not mentioning software use $(95.3 \%)$ being highlighted (Table 1$)$.

Concerning the Participants $(\mathrm{N}=1,671)$ and Data collection strategies $(\mathrm{N}=1,870)$, some studies were carried out with more than one type in each variable. Patients (52.0\%) and Professionals (39.6\%) most frequently constituted the sample in the qualitativestudies. Family (12.1\%) and other participants $(5.4 \%)$ completed the findings. The individual interview $(80.50 \%)$ was the most frequentstrategy, followed by the focus group (29.00\%) and other strategies (7.54\%).

According to the comparative analysis of the Framework, statistical significance was observed regarding the studies with professionals $(\mathrm{p}<0.001)$ and family $(\mathrm{p}<0.013)$. Considering the data collection strategy, significance was observed regarding the use of the focus group $(\mathrm{p}<0.006)$ (Table 3). 


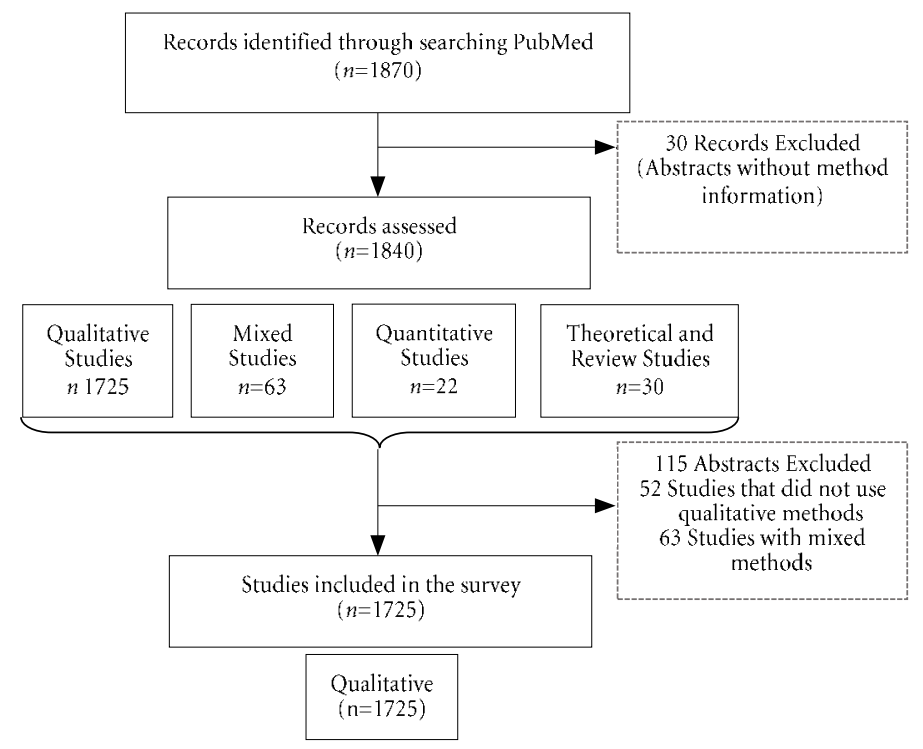

Figure 1. Survey Flow Diagram.

Source: Elaborated by the authors.

\section{Discussion}

Healthcare organizations have shifted their focus to a patient-centred model. This means that health policies and decision-making process of health professionals involves the patient, their experiences and their expectations. Qualitative research in biomedical field is the main scientific support to improve the policies needed for these models and achieving favourable patient outcomes. In this sense, support for improving qualitative health research may help researchers and journals better understand and structure the findings. Finally, models of care, health teams and patients will have benefits ${ }^{3,12}$.

From the number of qualitative studies published, the findings draw attention to the growth in this research over the last 40 years. To the best of our knowledge, there are no surveys that highlight the reality of these publications for the international scientific community.

The articles were analysed from their abstracts, which limited the amount of data available for analysis. The term "Qualitative Study" was used for the search because it is the expression most used in the qualitative studies in health. The search through the MeSH Term "Qualitative Research" was more limited and suggests a revi- sion of the expression chosen as the MeSH Term for the biomedical literature.

In addition, only PubMed was used as a database. An interesting survey on respiratory diseases in China analysed 10 years of literature also using PubMed as the database $\mathrm{e}^{13}$ and, despite the long period studied and the important comparative analyses performed, the authors discussed the research status in only three regions of China. In relation to these points, the present surveyanalysed a shorter period in the biomedical literature, however, covered issues with great potential for generalization of the results.

A survey of the methodological structure of qualitative research has the potential to not only provide a representation of the results, but also a basis for the construction of better structured research. The pilot study was an important tool for improving the validation process of these results and helped to predict and avoid biases.

The large number of journals included in this survey shows how widespread the qualitative study is in the biomedical literature. A concentration of $12.1 \%$ of the publications in five wellknown journals was found. The journals publish themes from several Health Knowledge Areas, i.e. medicine, nursing, physical rehabilitation, and health policy. The list group the five main jour- 
Table 1. The five main journals and the structural characteristics of the qualitative studies, 2016.

\begin{tabular}{|c|c|c|c|}
\hline Variables & Number of Studies & $(\%)$ & Impact Factor (2017) \\
\hline \multicolumn{4}{|l|}{ Journal $(\mathrm{N}=1,725)$} \\
\hline BMJ open & 57 & 3.3 & 2.41 \\
\hline PLOS ONE & 48 & 2.8 & 2.77 \\
\hline Journal of Clinical Nursing & 46 & 2.7 & 1.64 \\
\hline Disability and Rehabilitation & 29 & 1.7 & 2.04 \\
\hline Health Expectations & 27 & 1.6 & 2.18 \\
\hline Other $(n=615)$ & 1518 & 87.9 & \\
\hline \multicolumn{4}{|l|}{ Verbs $(\mathrm{N}=1,725)$} \\
\hline To Explore & 651 & 37.7 & \\
\hline To Examine & 159 & 9.2 & \\
\hline To Understand & 132 & 7.8 & \\
\hline To Describe & 131 & 7.6 & \\
\hline To Identify & 121 & 7.0 & \\
\hline Other $(n=147)$ & 531 & 30.7 & \\
\hline \multicolumn{4}{|l|}{ Sample size $(N=1,390)$} \\
\hline \multirow{2}{*}{\multicolumn{4}{|c|}{$\begin{array}{l}\text { Mean: 29.56; SD: 20.68; Mode: 20.00 Min: 1.00; Q1: } \\
\text { 15.00; Median: 23.00; Q3: 37.00; Max: } 99.00\end{array}$}} \\
\hline & & & \\
\hline $1-10$ & 152 & 10.94 & \\
\hline $11-20$ & 468 & 33.67 & \\
\hline $21-30$ & 294 & 21.15 & \\
\hline$>30$ & 476 & 34.24 & \\
\hline \multicolumn{4}{|l|}{ Framework mentioned $(\mathrm{N}=325)$} \\
\hline Grounded theory & 156 & 9.04 & \\
\hline Phenomenological analysis & 66 & 3.83 & \\
\hline Framework analysis approach & 23 & 1.33 & \\
\hline Ethnographic study & 6 & 0.35 & \\
\hline Graneheim and Lundman's approach & 4 & 0.23 & \\
\hline \multicolumn{4}{|l|}{ Software use mentioned $(\mathrm{N}=1,725)$} \\
\hline Yes & 81 & 4.70 & \\
\hline No & 1644 & 95.30 & \\
\hline
\end{tabular}

Source: Elaborated by the authors.

Table 2. The five health themes most published, according to the areas of knowledge of the qualitative studies, 2016.

\begin{tabular}{|c|c|c|c|c|c|}
\hline \multirow{2}{*}{ Health Themes } & \multicolumn{4}{|c|}{ Health Knowledge Areas } & \multirow{2}{*}{ Total (\%) } \\
\hline & Nursing & Medicine & Psychology & Public Health & \\
\hline \multirow[t]{2}{*}{ Health Management } & 27 & 25 & 22 & 130 & $204(12.0)$ \\
\hline & 18.88 & 7.27 & 4.27 & 17.98 & \\
\hline \multirow[t]{2}{*}{ Women Heath } & 9 & 28 & 82 & 50 & $169(9.8)$ \\
\hline & 6.29 & 8.14 & 15.92 & 6.92 & \\
\hline \multirow[t]{2}{*}{ Mental Health } & 14 & 36 & 60 & 56 & $166(9.6)$ \\
\hline & 9.79 & 10.47 & 11.65 & 7.75 & \\
\hline \multirow[t]{2}{*}{ Teaching in Health } & 38 & 22 & 12 & 47 & $119(6.9)$ \\
\hline & 26.57 & 6.40 & 2.33 & 6.50 & \\
\hline \multirow[t]{2}{*}{ Infectiology } & 0 & 16 & 16 & 78 & $110(6.4)$ \\
\hline & 0.00 & 4.65 & 3.11 & 10.79 & \\
\hline
\end{tabular}

Fisher's exact test: $\mathrm{p}<0.001$.

Source: Elaborated by the authors. 

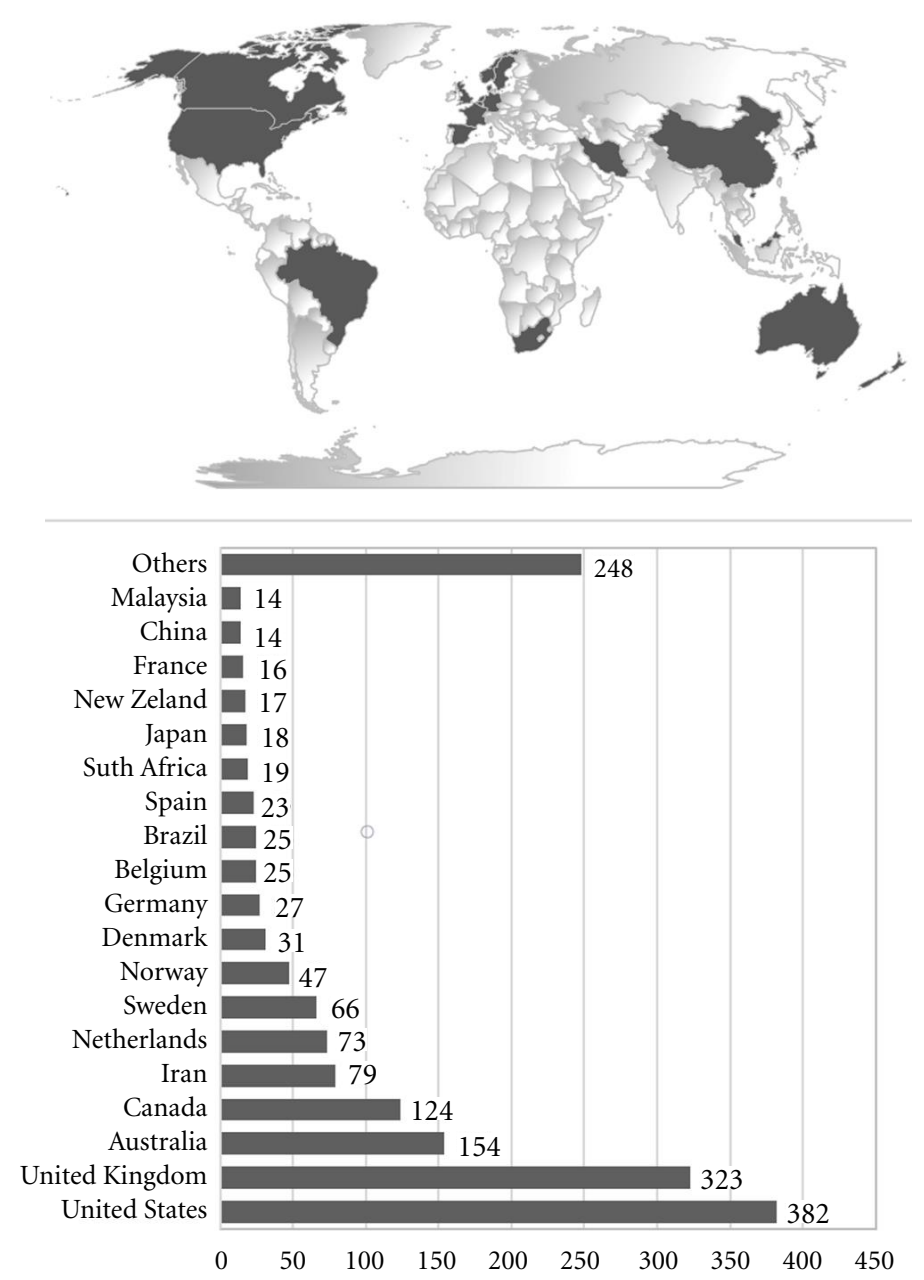

Figure 2. Country of the authors' academic affiliation in qualitative studies published, 2016.

Source: Elaborated by the authors.

nals and highlights the importance of these publications, mainly because they are high-impact journals.

Despite the number of qualitative research publications in high-impact journals, the growth is still slow. This slow process is a result of the paradigmatic obstacle prevalent in the biomedical literature, which undermines the scientific recognition of qualitative studies in the health knowledge areas ${ }^{14}$. On the other hand, the growth in publications denotes a real need for answers to research questions which quantitative studies are not able to provide in health settings ${ }^{15}$. In this sense, the tendency is for both paradigms, quan- titative and qualitative, to be used together to improve health practices.

Statistically significant findings confirm the multiplicity of the areas and themes involved in the growth of the publication of qualitative studies. Specifically, it is interesting to observe that the qualitative publications in infectology are mainly related to HIV/AIDS. The increase in publication in Public Health confirms that non-biomolecular research questions are a reality for this area. Studies involving lifestyle changes and treatment adherence make Infectiology rich in psychosocial issues, this being very important for health practices ${ }^{16}$. A similar observation 
Table 3. Analysis of the Framework according to the structural characteristics of the published qualitative studies, 2016.

\begin{tabular}{|c|c|c|c|c|c|c|}
\hline & \multicolumn{5}{|c|}{ Framework } \\
\hline & & Ethnographic & $\begin{array}{c}\text { Framework } \\
\text { Analysis }\end{array}$ & $\begin{array}{c}\text { Graneheim } \\
\text { and Lundman's }\end{array}$ & $\begin{array}{l}\text { Grounded } \\
\text { Theory }\end{array}$ & $\begin{array}{c}\text { Phenomenological } \\
\text { Analysis }\end{array}$ \\
\hline \multicolumn{7}{|l|}{ Participants } \\
\hline \multirow{4}{*}{$\begin{array}{l}\text { Patients } \\
(\mathrm{p}=0.055)\end{array}$} & Yes & 3 & 9 & 3 & 94 & 49 \\
\hline & & 1.51 & 4.52 & 1.51 & 47.24 & 24.62 \\
\hline & No & 3 & 14 & 1 & 62 & 17 \\
\hline & & 2.38 & 11.11 & 0.79 & 49.21 & 13.49 \\
\hline \multirow{4}{*}{$\begin{array}{l}\text { Families } \\
(\mathrm{p}=0.013)\end{array}$} & Yes & 1 & 7 & 1 & 10 & 9 \\
\hline & & 2.78 & 19.44 & 2.78 & 27.78 & 25.00 \\
\hline & No & 5 & 16 & 3 & 146 & 57 \\
\hline & & 1.73 & 5.54 & 1.04 & 50.52 & 19.72 \\
\hline \multirow{4}{*}{$\begin{array}{l}\text { Workers } \\
(p<0.001)\end{array}$} & Yes & 3 & 16 & 2 & 58 & 9 \\
\hline & & 2.86 & 15.24 & 1.90 & 55.24 & 8.57 \\
\hline & No & 3 & 17 & 2 & 98 & 57 \\
\hline & & 1.36 & 3.18 & 0.91 & 44.55 & 21.91 \\
\hline \multirow{4}{*}{$\begin{array}{l}\text { Students } \\
(\mathrm{p}=0.569)\end{array}$} & Yes & 0 & 0 & 0 & 1 & 1 \\
\hline & & 0.00 & 0.00 & 0.00 & 50.00 & 50.00 \\
\hline & No & 06 & 23 & 4 & 155 & 65 \\
\hline & & 1.86 & 7.12 & 1.24 & 47.99 & 21.67 \\
\hline \multicolumn{7}{|l|}{$\begin{array}{l}\text { Collection } \\
\text { Strategies }\end{array}$} \\
\hline \multirow{4}{*}{$\begin{array}{l}\text { Number of } \\
\text { Strategies } \\
(\mathrm{p}=0.002)\end{array}$} & 1 & 2 & 17 & 3 & 132 & 60 \\
\hline & & 0.74 & 6.30 & 1.11 & 48.89 & 22.22 \\
\hline & 2 & 3 & 6 & 1 & 22 & 2 \\
\hline & & 7.14 & 14.29 & 2.38 & 52.38 & 4.76 \\
\hline \multirow{4}{*}{$\begin{array}{l}\text { Individual } \\
\text { Interviews } \\
(\mathrm{p}=0.122)\end{array}$} & Yes & 4 & 20 & 4 & 133 & 56 \\
\hline & & 1.52 & 7.58 & 1.52 & 50.38 & 21.21 \\
\hline & No & 1 & 3 & 0 & 21 & 6 \\
\hline & & 2.08 & 6.25 & 0.00 & 43.75 & 12.50 \\
\hline \multirow{4}{*}{$\begin{array}{l}\text { Focus Group } \\
(\mathrm{p}=0.006)\end{array}$} & Yes & 3 & 8 & 1 & 38 & 5 \\
\hline & & 4.17 & 11.11 & 1.39 & 52.78 & 6.94 \\
\hline & No & 2 & 15 & 3 & 116 & 57 \\
\hline & & 0.83 & 6.25 & 1.25 & 48.33 & 23.75 \\
\hline \multirow{4}{*}{$\begin{array}{l}\text { Participant } \\
\text { Observation } \\
(\mathrm{p}=0.455)\end{array}$} & Yes & 0 & 0 & 0 & 1 & 0 \\
\hline & & 0.00 & 0.00 & 0.00 & 33.33 & 0.00 \\
\hline & No & 5 & 23 & 4 & 153 & 62 \\
\hline & & 1.62 & 7.44 & 1.29 & 49.51 & 20.06 \\
\hline \multirow[t]{4}{*}{ Software Use } & Yes & 0 & 1 & 0 & 4 & 0 \\
\hline & & 0.00 & 16.67 & 0.00 & 66.67 & 0.00 \\
\hline & No & 6 & 22 & 4 & 152 & 66 \\
\hline & & 1.88 & 6.90 & 1.25 & 47.65 & 20.69 \\
\hline
\end{tabular}

Source: Elaborated by the authors.

was noted in the qualitative studies in Women's Health regarding the focus on psychology issues. Traditional healthcare models for pregnant women have focused on care protocols. However, these models make it difficult to respond to the psychosocial issues of this public ${ }^{17,18}$. The need for non-pragmatic responses is mainly observed in specific care such as care for pregnant adolescents ${ }^{19,20}$. In this sense, the triggering questions for in-depth clinical situation analysis are the scientific tools needed to address psychosocial issues in the health practice ${ }^{21}$. This helps health providers to understand the people they care for, not just the diseases they treat. 
Our map helps to demonstrate that the trend in qualitative health publications is a global reality and that it is part of the scientific investments from the world's largest research centers ${ }^{16}$. The U.S. and U.K. are the largest investors in research and development in healthcare and life science in the world. This representation of the publications also seems to portray the difference in health priorities between emerging and developed countries. The authors of the studies analysed have academic affiliation in countries where reducing mortality rates are not the only or the main concerns. Among the 19 countries listed in the present study, 12 are among the world's largest investors in scientific research and development. These findings show that the dominant group in global research has directed part of its qualitative research investments toward other sectors of healthcare and life science ${ }^{16}$.

It can also be seen that the characteristics of the qualitative studies follow a tendency regarding the language. Some qualitative researchers use language that is unfamiliar to the health sciences, since they have a base in the social and human sciences $^{22,23}$. Therefore, the qualitative objective should be directed toward a focus recognized by the health sciences field. At the methodological structure level, the guide function of the verb used helps to give scientific rigor to qualitative studies. The suggestion to maintain a standard regarding the objectives of the qualitative studies in health settings is intended to preserve the rigor of the results and provide clarity for the biomedical literature reader. The expressive frequency of the verb "to explore" denotes how qualitative researchers might not propose such specific goals as might be the case in human science studies ${ }^{23}$. Adaptation to the biomedical literature language might include the adoption of broader expressions to encompass the characteristics of both paradigms.

The present survey aimed to explore the characteristics of the studies in order to improve the methodological structure of qualitative research. Understanding structural variables such as sample size, software use and the framework used helps to clarify the qualitative research results. Often, qualitative researchers are unclear regarding sample size, and the epidemiological representation of this variable might help to understand it in this type of research. This lack of clarity possibly takes place because it is not possible to previously know the " $\mathrm{N}$ " and whether it will be sufficient to respond to the research objectives $^{24}$. In this survey, the studies that hadsample sizes above 30 were those that used the Focus Group as the collection strategy. This is the rationale for the higher $\mathrm{N}$ in comparison with the studies that used the Individual Interview as a collection strategy. These results suggest an interesting trend, since qualitative sample sizes are usually defined by the theoretical saturation technique coined by Glaser and Strauss ${ }^{25}$ for Grounded Theory analysis. Finally, paradigmatic issues explain the low use of software for qualitative analysis. Those qualitative researchers who used software also often used Grounded Theory analysis.

Observation and interview are the main methods used to understand a particular phenomenon from the viewpoint of those who have experienced it. The results can guide health professionals in planning treatment and approaches to patient care that meet patients' needs. Thus, findings from qualitative studies can be used to inform policy and protocol development ${ }^{3,26}$.

In conclusion, knowledge about the research structure, the journals and the profile of the authors is important to construct solid thinking regarding the exposure of the best scientific results of qualitative health research. This is because a difference in the paradigm means a difference in the intervention ${ }^{27,28}$. The investigation of the structure of the qualitative studies included in this review helps qualitative researchers to structure their studies better and consequently their interventions in health settings. Thus, the rationale regarding the techniques used for the sample and analysis strategies will be better thought out. The improved structuring of a qualitative research extends the effective communication between health professionals andresearchers, and support in the management of clinical situation $s^{26,29}$. Finally, criticisms regarding the lack of rigor and validity in qualitative health studies can be responded to by making the study results clearer for the biomedical literature ${ }^{30}$. 


\section{Collaborations}

RA Bastos worked on the design, data collection and final text. The authors VLP Alves, RMC Sena, JVF Jesus and L Rodrigues worked on data collection and critical review of the research. The authors FGC Surita and ER Turato worked on the methodology, critical review and final text of the article.

\section{Acknowledgements}

We thank the research group from the Laboratory of Clinical-Qualitative Research (LPCQ) in the Psychiatry Department of the School of Medical Sciences at the University of Campinas for their important contributions and management support throughout this study.

\section{References}

1. Yamazaki H, Slingsby BT, Takahashi M, Hayashi Y, Sugimori H, Nakayama T. Characteristics of qualitative studies in influential journals of general medicine: a critical review. Biosci Trends 2009; 3(6):202-209.

2. Malterud $\mathrm{K}$. The art and science of clinical knowledge: evidence beyond measures and numbers. Lancet 2001; 358(9279):397-400.

3. Hedges C, Williams B. Anatomy of Research for Nurses. Indianapolis: Sigma Theta Tau International; 2014.

4. Brooke JM, Mallion J. Implementation of evidence -based practice by nurses working in community settings and their strategies to mentor student nurses to develop evidence-based practice: A qualitative study. Int J Nurs Pract 2016; 22(4):339-347.

5. Honeycutt S, Hermstad A, Carvalho ML, Arriola KRJ, Ballard D, Escoffery C, Kegler MC. Practice to Evidence: Using Evaluability Assessment to Generate Practice-Based Evidence in Rural South Georgia. Health Educ Behav 2017; 44(3):454-462.

6. Ednell A-K, Siljegren S, Engström $\AA$. The ICU patient diary-A nursing intervention that is complicated in its simplicity: A qualitative study. Intensive Crit Care Nurs 2017; 40:70-76.

7. Bishop AC, Macdonald M. Patient Involvement in Patient Safety: A Qualitative Study of Nursing Staff and Patient Perceptions. J Patient Saf 2017; 13(2):82-87.

8. Feizolahzadeh S, Vaezi A, Mirzaei M, Khankeh H, Taheriniya A, Vafaeenasab M, Khorasani-Zavareh D. Barriers and facilitators to provide continuity of care to dischargeable patients in disasters: A Qualitative Study. Injury 2019; 50(4):869-876.

9. Taquette SR, Minayo MCS. The main characteristics of qualitative studies carried out by doctors in Brazil: a literature review. Cien Saude Colet 2015; 20(8):24232430.

10. Hawkins DT. Bibliometrics of electronic journals in information science. Information Res 2001; 7(1):1.

11. Kokol P, Vošner HB, Železnik D, Vošner J, Saranto K. Bibliometric Patterns of Research Literature Production on Nursing Informatics Competence. J Nurs Educ 2015; 54(10):565-571.

12. King BJ, Gilmore-Bykovskyi AL, Roberts TJ, Kennelty KA, Mirr JF, Gehring MB, Dattalo MN, Kind AJH Impact of Hospital Context on Transitioning Patients From Hospital to Skilled Nursing Facility: A Grounded Theory Study. Gerontologist 2017; 58(3), 521-529.

13. Ye B, Du T, Xie T, Ji J-T, Zheng Z-H, Liao Z, Hu L-H, Li Z-S. Scientific publications in respiratory journals from Chinese authors in various parts of North Asia: a 10-year survey of literature. BMJ Open 2014; 4:e004201.

14. Bosi MLM. Qualitative research in collective health: overview and challenges. Cien Saude Colet 2012; 17(3):575-586

15. Baxter S, Killoran A, Kelly MP, Goyder E. Synthesizing diverse evidence: the use of primary qualitative data analysis methods and logic models in public health reviews. Public Health 2010; 124(2):99-106.

16. Battelle Memorial Institute. 2014 Global R\&D Funding Forecast. Columbus: Battelle; 2014. 
17. Chikalipo MC, Nyondo-Mipando L, Ngalande RC, Muheriwal SR, Kafulafula UK. Perceptions of pregnant adolescents on the antenatal care received at Ndirande Health Centre in Blantyre, Malawi. Malawi Med J 2018; 30(1):25-30.

18. Oliveira RLA, Fonseca CRB, Carvalhaes MABL, Para$\mathrm{da}$ CMGL. Evaluation of pre-natal care from the perspective of different models in primary care. Rev Lat Am Enferm 2013; 21(2):546-553.

19. Franco-Ramírez JA, Cabrera-Pivaral CE, ZárateGuerrero G, Franco-Chávez SA, Covarrubias-Bermúdez MÁ, Zavala-González MA. Social representations of Mexican pregnant teenagers about the puerperal care, lactation, and newborn care. Bol Med Hosp Infant Mex 2018; 75(3):153-159.

20. Tinago CB, Ingram LA, Frongillo EA, Blake CE, Engelsmann B, Simmons D. Understanding Conceptualizations of Pregnancy and Planning for Pregnancy Among Adolescent Girls and Young Women in Harare, Zimbabwe. Qual Health Res 2018; 28(9):15091519.

21. Faria-Schützer DB, Surita FGC, Alves VLP, Vieira CM, Turato ER. Emotional Experiences of Obese Women with Adequate Gestational Weight Variation: A Qualitative Study. PLoS One 2015; 10(11): 0141879.

22. Marsiglia RMG. Emerging themes in social sciences and public/collective health: production of knowledge at its interface. Saude Soc 2013; 22(1):32-43.

23. Minayo MCS. O desafio do conhecimento: Pesquisa qualitativa em saúde. São Paulo: Hucitec; 2013.

24. Malterud K, Siersma VD, Guassora AD. Sample Size in Qualitative Interview Studies: Guided by Information Power. Qual Health Res 2015; 26(13):1753-1760.

25. Glaser B, Strauss A. The discovery of grounded theory: Strategies for qualitative research. New York: Aldine de Gruyter; 1999.
26. Hepworth J, Kay M. General practitioners learning qualitative research: A case study of postgraduate education. Aust Fam Physician 2015; 44(10):760-763.

27. Becker HS. The epistemology of qualitative research. Braz J Empirical Legal Stud 2014; 1(2):184-199.

28. Malterud K, Siersma VD, Guassora AD. Sample Size in Qualitative Interview Studies. Qual Health Res 2016; 26(13):1753-1760.

29. Chu H, Zeng L, Fetters MD, Li N, Tao L, Shi Y, Zhang H, Wang X, Li F, Zhao Y. How novice, skilled and advanced clinical researchers include variables in a case report form for clinical research: a qualitative study. BMJ Open 2017; 7(9):e016760.

30. Boddy CR. Sample size for qualitative research. Qual Market Res Int J 2016; 19(4):426-432.

Article submitted 02/01/2020

Approved 09/05/2020

Final version submitted 11/05/2020

Chief Editors: Romeu Gomes, Antônio Augusto Moura da Silva 